\title{
Early Outcome Following Modified Blalock-Taussig Shunt in Cyanotic Congenital Heart Diseases: Determinants of Morbidity and Mortality
}

\author{
Shady Abdelmoneim* Hany Faisal, Hassan Hassan and Hany El-Domiaty \\ Department of Cardiothoracic Surgery, Faculty of Medicine, Suez Canal University, Egypt
}

\begin{abstract}
Background: Modified Blalock-Taussig Shunt is the most commonly used palliative shunt procedure in congenital heart disorders and is associated with significant morbidity and mortality. Aim: to improve the outcome following this surgical intervention. Subjects and Methods: Data about all children undergoing Modified Blalock-Taussig Shunt in Suez Canal University Hospitals and Cairo University Specialized Children Hospital in the time interval between March 2014 and February 2015 has been collected in three phases; pre- intra- and post-operatively then analyzed statistically. Results: Mortality in our study was 50\%. The main risk factors for mortality in our study were weight urgency pre-operative prostene infusion cardiopulmonary bypass graft size and wound infection. Regarding shunt occlusion weight shunt size and intra-operative administration of protamine were statistically significant risk factors. Conclusion: Mortality rates decreased significantly with increasing weight. Cardiopulmonary Bypass graft size and wound infection were noted to be definite risk factors for mortality. Regarding acute shunt occlusion risk factors of statistical importance were weight intra-operative protamine and graft size.
\end{abstract}

Keywords: Cyanosis palliative Shunt Cardiopulmonary Bypass

\section{Introduction}

Congenital heart disease is one of the commonest congenital defects with an incidence of $0.8 \%{ }^{(1)}$. It remains the leading cause of death in children with congenital malformations. The incidence is higher among stillborns abortuses and premature infants ${ }^{(1)}$. Surgical management of congenital heart disease include both definitive and palliative procedures. Although definitive repair of congenital heart disease in the neonatal period is the de- sired preference staged approach is used in many types of anomalies ${ }^{(1)}$. In patients with diminished pulmonary blood flow systemic-pulmonary artery shunts remain important for palliation. Though seemingly simple Modified Blalock-Taussig Shunt is associated with significant morbidity and mortality ${ }^{(3)}$. Complications following Modified Blalock-Taussig Shunt can be classified into early and late complications. Early complications include acute shunt blockage perigraft seroma and pseudoaneurysm formation ${ }^{(2)}$. The most serious late 
complication is late shunt obstruction. These complications are associated with increased mortality. Incidence and causes of morbidity and mortality following Modified Blalock-Taussig Shunt differ between various countries and centers. Various factors have been implied as risk factors for morbidity and mortality following Modified Blalock-Taussig Shunt for example patient $s$ anatomy low birth weight increased shunt size/ weight ratio ${ }^{(4,5)}$. However factors relating to acute blockage of Modified Blalock-Taussig shunts (MBTS) have not been well described in the literature ${ }^{(4)}$.

\section{Subjects and Methods}

This study has been carried out in Suez Canal University Hospitals and Cairo University Specialized Children Hospital to collect data about patients undergoing palliation with Modified Blalock-Taussig Shunt to describe the different factors associated with increased morbidity and mortality in the early post-operative period following this life-saving surgical procedure. This comprises the first thirty days following the shunt procedure. Mortality includes both intra- and post-operative deaths whereas morbidity refers to a spectrum of complications related to the surgical maneuver which can result in unplanned re-operation longer duration of mechanical ventilation ICU stay, and hospital stay.

Study Design and Setting: This study has been carried out on a prospective basis.

Target population: Children with congenital heart disease associated with reduced pulmonary blood flow fulfilling the following inclusion criteria: i) All children with cyanotic congenital heart diseases who have received a palliative Modified Blalock-Taussig Shunt in Cairo University Specialized Children Hospital in the time interval between March 2014 and Febru- ary 2015 with or without cardiopulmonary bypass and with or without concomitant Patent Ductus Arteriosus (PDA) ligation. ii) Age: from birth to 16 years. Exclusion criteria included i) Patients who have received other major concomitant procedures in the same setting of shunt procedure (such as those for hypoplastic left heart syndrome) have been excluded from the study. ii) Patients whose guardians refuse to participate in the study.

Sampling: Due to the relative infrequency of congenital heart anomalies and the limited timeframe available for the study we have used a convenient non-proprietary sampling technique. All children meeting the inclusion criteria mentioned before in the time interval from March 2014 to February 2015 have been included with exclusion of patients who have receive other major concomitant procedures in the same setting.

Data Collection:

Data has been collected in three stages; pre intra and post-operatively. i) Preoperative data Complete history taking clinical examination investigations and imaging techniques. A critical preoperative status has been considered in cases of pre-operative ventilatory support acidosis ( $\mathrm{pH}$ less than 7.35) shock and inotropic support. ii) Operative Data: Timing of the procedure (elective or urgent) Surgical approach (Median sternotomy left thoracotomy or right thoracotomy) Ligature of the ductus. Use of Cardiopulmonary Bypass Heparinization and reversal by protamine if needed Graft site and size. iii) Post-Operative Data: Post-operative blood loss (total amount of blood lost in the chest drains in $\mathrm{ml}$ ) Post-operative oxygen saturation Post-operative use of anticoagulants. Incidence of different postoperative complications during the first thirty days post-operatively including early deaths acute shunt thrombosis/ occlusion 
arrhythmias perigraftseroma pseudoaneurysm formation around subclavian artery low cardiac output requiring inotropic support post-operatively extubation failure (defined as reventilation in less than 96 hours following extubation) infection ventilator-associated pneumonia which may be complicated by sepsis and septic shock. Length of post-operative mechanical ventilation. Length of ICU and hospital stay. Incidence of early shunt intervention (either surgical or transcatheter) within the first thirty days post-operatively. Approvals from the Research Ethics Committee of the Faculty of Medicine Suez Canal University and the Research Ethics Committee of the Faculty of Medicine Cairo University were taken before starting field work. An informed consent for carrying out the surgical procedure was taken from the parents or other guardians of the patients.

\section{Statistical Analysis}

Collected data was coded entered and analyzed using Statistical Package for Social Science (SPSS version 22) for Windows.

\section{Results}

A) Pre-Operative Conditions: In our study the patients were in the range of 15 to 455 days old (106.2 \pm 110.278 days). Concerning the weight, it ranged from $2.5 \mathrm{~kg}$ to 8 $\mathrm{kg}(4.158 \pm 1.266 \mathrm{~kg})$; (table 1). The majority $(62.5 \%)$ were infants (<1-year-old) $32.5 \%$ were neonates ( $<30$ days old) and only $5 \%$ were children ( $>$ one year old). The mean Pre-Operative oxygen saturation was $63.85 \%$ with a standard deviation of \pm $5.947 \%$. It ranged from $55 \%$ to $80 \%$. Table 2 shows the relative frequencies of different pathologies diagnosed pre-operatively by echocardiography. Most patients (30\%) had Tetralogy of Fallot (TOF). Only 30\% of patients have Major Aoto-Pulmonary Collaterals (MAPCAs). Only $25 \%$ of patients in our series were operated upon on an urgent basis. Urgency here means that the patient was admitted pre-operatively in an ICU. However only $25 \%$ of patients needed pre-operative prostene (prostaglandin E2) infusion and only $7.5 \%$ were mechanically ventilated prior to surgical intervention.

Table 1: Distribution of age and weight among study population

\begin{tabular}{|l|c|c|c|c|c|}
\hline & N & Minimum & Maximum & Mean & SD \\
\hline Age (days) & 40 & 15 & 455 & 106.20 & 110.278 \\
\hline Weight (kg) & 40 & 2.5 & 8.0 & 4.158 & 1.2665 \\
\hline
\end{tabular}

The diameter of Right Pulmonary Artery (RPA) (range 2.5-9.2 mm mean \pm SD $4.235 \pm 1.448 \mathrm{~mm}$ ). Regarding the Left Pulmonary Artery (LPA) the diameter ranged from $2.8 \mathrm{~mm}$ to $6 \mathrm{~mm}$ (mean $\pm \mathrm{SD}$ $4.115 \pm 0.796 \mathrm{~mm}$ ). MacGoon index was calculated by dividing the sum of diameters of RPA and LPA by the diameter of descending Aorta at the level of diaphragm. (range 1-1.6 mean \pm SD, 1.267 \pm 0.175 ).

B) Intra-Operative Conditions

The preferred surgical approach for most surgeons was standard median sternoto- my (85\%). Only $15 \%$ performed the MBTS through a thoracotomy incision either left (7.5\%) or right (7.5\%). $72.5 \%$ of shunts were performed without Cardio-Pulmonary Bypass (CPB). In $52.5 \%$ of patient's PDA was ligated. Only $5 \%$ of patients did not have PDA. (Tables 4 and 5). Concerning the graft size $35 \%$ of shunts were performed using a $4-\mathrm{mm}$ graft $32.5 \%$ were $3.5 \mathrm{~mm}$ $22.5 \%$ were $3 \mathrm{~mm}$ and just $10 \%$ were $5 \mathrm{~mm}$. $77.5 \%$ of shunts were performed on the right side while $22.5 \%$ were performed between left subclavian artery and LPA. 
Table 2: Pre-operative echocardiographic diagnosis and MAPCAs

\begin{tabular}{|c|c|c|c|c|c|c|c|c|c|}
\hline \multicolumn{8}{|c|}{ Echo Diagnosis $(n=40)$} & \multicolumn{2}{|c|}{ MAPCAs $(n=40)$} \\
\hline $\begin{array}{l}\text { CAVC- } \\
\text { SD PA }\end{array}$ & $\begin{array}{l}\text { HETERO- } \\
\text { TAXY }\end{array}$ & $\begin{array}{l}\text { PA/ } \\
\text { IVS }\end{array}$ & $\begin{array}{l}\text { PA / } \\
\text { VSD }\end{array}$ & $\begin{array}{l}\text { TA } \\
\text { PA }\end{array}$ & $\begin{array}{c}\text { TA } \\
\text { TGA }\end{array}$ & $\begin{array}{c}\text { TGA } \\
\text { VSD PS }\end{array}$ & TOF & $\begin{array}{l}\text { Without } \\
\text { MAPCAs }\end{array}$ & $\begin{array}{l}\text { With } \\
\text { MAPCAs }\end{array}$ \\
\hline 1 & 6 & 3 & 8 & 8 & 1 & 1 & 12 & 36 & 4 \\
\hline $2.5 \%$ & $15 \%$ & $7.5 \%$ & $20 \%$ & $20 \%$ & $2.5 \%$ & $2.5 \%$ & $30 \%$ & $90 \%$ & $10.0 \%$ \\
\hline
\end{tabular}

C) Post-Operative Conditions and Incidence of Different Complications

The mean post- shunt oxygen saturation was $77.3 \%$. The duration of post-operative mechanical ventilation ranged from one day to 12 days and that of ICU stay ranged from one day to 25 days. The minimum duration of hospital stay was one day while the maximum was 30 days. Shuntrelated mortality in our study was $50 \%$. Twenty-five percent of deaths occurred in the first 48 hours post-operatively while $50 \%$ of deaths occurred in the first 72 hours. Regarding the incidence of different shunt-related morbidities table 3 shows that $27.5 \%$ suffered from acute shunt occlusion with extremely low oxygen saturation and confirmed by echocardiography. Shunt overflow was diagnosed by oxygen saturation over $90 \%$ together with Qp:Qs ratio more than 1 (calculated from $A B G s$ and VBGs) and hemodynamic instability. $20 \%$ of patients had shunt overflow. Wound infection had complicated $30 \%$ of our patients while $15 \%$ had Ventilator Associated Pneumonia (VAP) and 10\% were complicated by sepsis. Extubation failure defined as re-intubation within 96 hours of extubation was reported in $40 \%$ of our patients while no cases of perigraft seromas were documented.

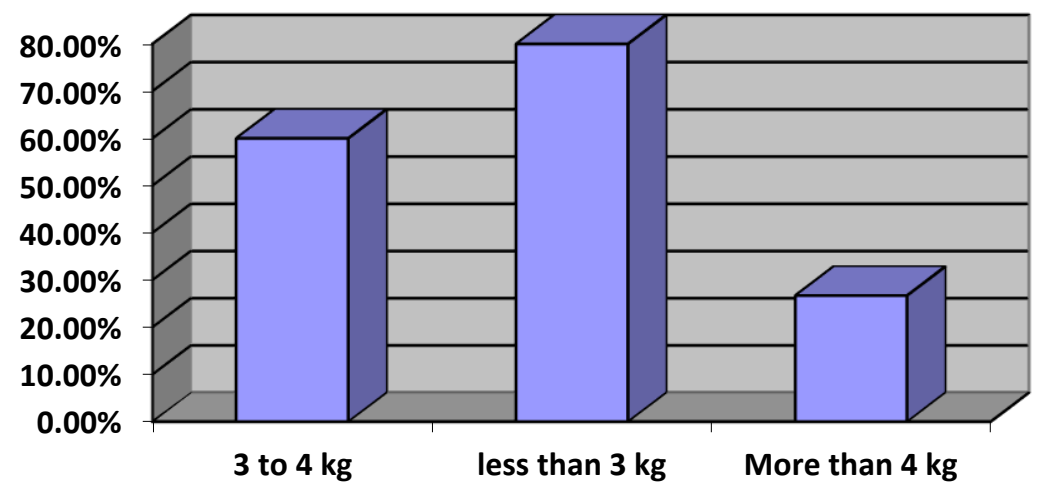

Figure 1: Mortality according to weight

Table 3: Incidence of different shunt-related post-operative complications (no. \%)

\begin{tabular}{|c|c|c|c|c|c|c|}
\hline $\begin{array}{c}\text { Shunt } \\
\text { Occlusion }\end{array}$ & $\begin{array}{c}\text { Shunt } \\
\text { Overflow }\end{array}$ & $\begin{array}{c}\text { Wound } \\
\text { Infection }\end{array}$ & VAP & Sepsis & $\begin{array}{c}\text { Extubation } \\
\text { Failure }\end{array}$ & Reopening \\
\hline 11 & 8 & 12 & 6 & 4 & 16 & 6 \\
\hline $27.5 \%$ & $20 \%$ & $30 \%$ & $15 \%$ & $10 \%$ & $40 \%$ & $15 \%$ \\
\hline
\end{tabular}

D) Risk Factors for Mortality

As previously mentioned mortality was reported in $50 \%$ of our patients. In $55 \%$ of these the direct cause of death was shunt occlusion while shunt overflow constituted $30 \%$ of mortality. Ventilator associated 
pneumonia (VAP) and sepsis were responsible for $10 \%$ of mortality cases. There was a statistically significant relationship between weight and mortality. Mortality rates decreased with increasing weight. This is further illustrated in figure 1. There was no statistically significant relationship between mortality and echo diagnosis MAPCAs or Down syndrome. There is a statistically significant difference in mor tality between urgent and elective cases. $90 \%$ of patients operated upon on an urgent basis did not survive while only $36.7 \%$ of elective patients have died. CPB is a definite risk factor for mortality with a statistically significant difference. $90.9 \%$ of patients put on CPB have died. Median sternotomy was associated with the highest mortality within surgical approaches. However, this was statistically insignificant. There was a statistical significance relationship between graft size and mortality; as mortality decreased with increasing graft size. Wound infection has a statistically significant relationship with mortality.

Table 4: Relationship between mortality and weight

\begin{tabular}{|l|c|c|c|c|c|c|}
\hline \multirow{2}{*}{} & \multicolumn{5}{|c|}{ Weight } \\
\cline { 2 - 7 } & \multicolumn{2}{|c|}{3 to $4 \mathrm{~kg}(\mathrm{n}=12)$} & \multicolumn{2}{c|}{ Less than 3 $\mathrm{kg}(\mathrm{n}=4)$} & \multicolumn{2}{c|}{ More than $4 \mathrm{~kg}(\mathrm{n}=4)$} \\
\cline { 2 - 7 } & $\begin{array}{c}\text { \% within } \\
\text { weight }\end{array}$ & $\begin{array}{c}\text { \% within } \\
\text { Mortality }\end{array}$ & $\begin{array}{c}\text { \% within } \\
\text { weight }\end{array}$ & $\begin{array}{c}\text { \% within } \\
\text { Mortality }\end{array}$ & $\begin{array}{c}\text { \% within } \\
\text { weight }\end{array}$ & $\begin{array}{c}\text { \% within } \\
\text { Mortality }\end{array}$ \\
\hline Mortality & $60.0 \%$ & $50.0 \%$ & $80.0 \%$ & $20 \%$ & $26.7 \%$ & $20.0 \%$ \\
\hline P value & \multicolumn{7}{|c}{$0.053^{*}$} \\
\hline
\end{tabular}

*: statistically significant difference

E) Risk Factors for Shunt Occlusion

There was no statistically significant relationship between age and shunt occlusion however more than half of mortality cases were noticed in neonates. Regarding weight of the patients it affected rate of shunt occlusion in a statistically significant manner. The risk of occlusion decreased dramatically with increasing weight. The surgical approach did not affect the incidence of shunt occlusion as there was no significant difference between the different approaches. The highest rate of shunt occlusion was noted in cases where a GORETEX graft size 3 was used (66.7\%) while no cases of shunt occlusion has been documented with graft size 5 . Also $54.5 \%$ of shunt occlusions were reported with grafts size 3 . This relationship is statistically significant. There was no statistically significant relationship between acute shunt occlusion and target pulmonary artery branch size.
F) Risk Factors for Shunt Overflow

MAPCAs were a definite risk factor for shunt overflow with statistical significance. Seventy-five percent of patients with MAPCAs have suffered from shunt overflow. No statistically significant relationship was found between shunt overflow and shunt size weight of patients or target pulmonary artery branch size.

\section{Discussion}

\section{A) Pre-operative Conditions}

Demographic Characteristics: the age of our patients ranges from $15-455$ days (mean 106.2 \pm 110.27 ). Infants (from one month to one year old) constitute most of our patients; $62.5 \%$ and $32.5 \%$ are neonates whilst just $5 \%$ are children. The high proportion of infants in our study can be explained by the fact that most neonates succumb to their illness and many surgeons prefer definitive repair in later childhood. 
Table 5: Relationship between mortality and urgency and pre-op. mechanical ventilation

\begin{tabular}{|c|c|c|c|c|c|c|c|c|}
\hline & \multicolumn{4}{|c|}{ Urgency } & \multicolumn{4}{|c|}{ Pre-op. Mech. Vent. } \\
\hline & \multicolumn{2}{|c|}{ Not urgent $(n=11)$} & \multicolumn{2}{|c|}{ Urgent $(n=9)$} & \multicolumn{2}{|c|}{ Not ventilated $(n=17)$} & \multicolumn{2}{|c|}{ Ventilated $(n=3)$} \\
\hline & $\begin{array}{l}\text { \% within } \\
\text { urgency }\end{array}$ & $\begin{array}{l}\% \text { within } \\
\text { mortality }\end{array}$ & $\begin{array}{l}\text { \% within } \\
\text { urgency }\end{array}$ & $\begin{array}{l}\text { \% within } \\
\text { mortality }\end{array}$ & $\begin{array}{l}\text { \% within } \\
\text { urgency }\end{array}$ & $\begin{array}{l}\text { \% within } \\
\text { mortality }\end{array}$ & $\begin{array}{l}\text { \% within } \\
\text { urgency }\end{array}$ & $\begin{array}{l}\% \text { within } \\
\text { mortality }\end{array}$ \\
\hline Mortality & $36.7 \%$ & $55.0 \%$ & $90.0 \%$ & $45.0 \%$ & $45.9 \%$ & $85.0 \%$ & $100.0 \%$ & $15.0 \%$ \\
\hline$P$ value & & & & & & 0.07 & (NS) & \\
\hline
\end{tabular}

*: statistically significant difference (NS): no statistically significant difference

Our work is not confined to specific age groups in contrast to other studies $(4,6-12)$. All of them have specifically studied the neonatal age group. On the other hand in the study performed by $\mathrm{Al}$ Jubair(13) patients from one week to one year old con- stituted $57.2 \%$ and $41.9 \%$ were over one year old. Just $16.5 \%$ in this series were younger than one week. Dirks et al (3) have studied patients from one to 74 days. In the series of Gedicke et al the age ranged from 2 days to 8 years ${ }^{(14)}$.

Table 6: Relationship between mortality and graft size

\begin{tabular}{|c|c|c|c|c|}
\hline & & & Mortality & $P$ value \\
\hline \multirow{4}{*}{$\begin{array}{l}\frac{0}{N} \\
\frac{\stackrel{N}{n}}{\frac{\pi}{v}}\end{array}$} & $3 \mathrm{~mm}$ & $\begin{array}{l}\mathrm{N} \\
\% \text { within graft size } \\
\% \text { within Death }\end{array}$ & $\begin{array}{c}8 \\
88.9 \% \\
40 \%\end{array}$ & \multirow{4}{*}{$0.02 *$} \\
\hline & $3.5 \mathrm{~mm}$ & $\begin{array}{l}\mathrm{N} \\
\% \text { within graft size } \\
\% \text { within Death }\end{array}$ & $\begin{array}{c}6 \\
46.2 \% \\
30 \%\end{array}$ & \\
\hline & $4 \mathrm{~mm}$ & $\begin{array}{l}\mathrm{N} \\
\% \text { within graft size } \\
\% \text { within Death }\end{array}$ & $\begin{array}{c}6 \\
42.9 \% \\
30 \%\end{array}$ & \\
\hline & $5 \mathrm{~mm}$ & $\begin{array}{l}\mathrm{N} \\
\% \text { within graft size } \\
\% \text { within Death }\end{array}$ & $\begin{array}{l}0 \\
0 \\
0\end{array}$ & \\
\hline
\end{tabular}

*: statistically significant difference

Also Shauq et al performed their study on patients aged from one day to 1045 days ${ }^{(15)}$. In Libya Maghur et al studied patients from 4 days to 15 years old ${ }^{(16)}$. Only $30 \%$ of our patients are known to have Down syndrome. This is because Down syndrome does not carry a higher risk for cyanotic congenital heart diseases. No available data in the literature documenting the exact proportion of Down syndrome among MBTS patients. The mean weight is $4.1 \pm 1.2 \mathrm{~kg}$ ranging from $2.5-8 \mathrm{~kg}$. Patients in Dirks et al's series ranged from 1.9 to $4.4 \mathrm{~kg}$ with a median of $2.9 \mathrm{~kg}(3)$. While the range was from $1.5-51 \mathrm{~kg}$ in
Mckenzie et al's study(17). Maghur at al studied patients weighing 3 to $31 \mathrm{~kg}^{(16)}$. The mean weight in the study performed by Sivakumar et al was $3.1 \pm 0.7 \mathrm{~kg}$ and the smallest patient was $2.1 \mathrm{~kg}^{(10)}$. Myers et al studied patients weighing $<3 \mathrm{~kg}^{(18)}$.

Pre-operative conditions: In our study preoperative oxygen saturation ranges from $55-80 \%$ with a mean of $63.85 \pm 5.9 \%$. Mean pre-operative oxygen saturation in the study performed by Al Jubair et al was $71.7 \pm 16.5 \%{ }^{(13)}$. Concerning the preoperative echocardiographic diagnosis patients with single ventricle physiology constitute $67.5 \%$ while the remainder are 
amenable to biventricular repair. The same pattern was observed in the series of McKenzie et $\mathrm{al}^{(17)}$. This is in contrast to the studies performed by Dirks et al(3) and Petrucci et al(4) in which the majority of patients were suitable for later biventricular repair. Most of our patients have Tetralogy of Fallot (30\%) $20 \%$ have PA/ VSD and only $7.5 \%$ have PA/ IVS. Also TOF represented $72 \%$ of patients in Williams et al' $s$ study(19). This is in contrast to the study performed by Fermanis et al in which TOF only represented $7.8 \%$ of patients ${ }^{(20)}$. The $\mathrm{PA} /$ IVS group in Petrucci et al series constituted $14 \%$ (4) while TOF patients represtented only $24 \%$ of the patients in O'Connor et al's series ${ }^{(8)}$. In the study performed by Sivakumar et al $30 \%$ of patients had PA/ VSD and $15 \%$ had PA/ IVS ${ }^{(10)}$. $25 \%$ of patients in our series were operated upon on an urgent basis. Patients mechanically ventilated and those on prostaglandin $\mathrm{E} 1$ infusion are considered urgent cases. 7.5\% of our patients were mechanically ventilated before the surgical intervention and $25 \%$ needed PG E1 infusion. $42 \%$ of patients in Swain et al' $\mathrm{s}$ study needed preoperative PG E1 infusion ${ }^{(21)}$ and $15.6 \%$ were performed on an urgent basis in the series of Shauq et $\mathrm{al}^{(15)}$. Sivakumar et al noticed that $50 \%$ of their patients needed preoperative PG E1 infusion (10). As regards pulmonary artery size the diameter of the RPA ranges from 2.5 to $9.2 \mathrm{~mm}$ with a mean of $4.2 \pm 1.4 \mathrm{~mm}$ and the diameter of the LPA range from 2.8 to $6 \mathrm{~mm}$ with a mean of $4.1 \pm 0.8 \mathrm{~mm}$. The MacGoon index range from 1 to 1.6. Sivakumar at al recorded a mean diameter of $3.9 \pm 0.44 \mathrm{~mm}$ for the RPA and $3.69 \pm 0.79 \mathrm{~mm}$ for the $\mathrm{LPA}^{(10)}$. Ahmad et al recorded almost similar measurements; RPA: $3 \pm 0.2 \mathrm{~mm}$ and LPA: $2.9 \pm 0.2 \mathrm{~mm}$ (9).

Table 7: Relationship between shunt occlusion and weight

\begin{tabular}{|l|c|c|c|c|c|c|}
\hline \multirow{2}{*}{} & \multicolumn{5}{|c|}{ Weight } \\
\cline { 2 - 7 } & \multicolumn{2}{|c|}{3 to 4 $\mathrm{kg}(\mathrm{n}=6)$} & \multicolumn{2}{c|}{$<3 \mathrm{~kg}(\mathrm{n}=4)$} & \multicolumn{2}{c|}{$>4 \mathrm{~kg}(\mathrm{n}=1)$} \\
\cline { 2 - 7 } & $\begin{array}{c}\% \text { within } \\
\text { weight }\end{array}$ & $\begin{array}{c}\% \text { within } \\
\text { occlusion }\end{array}$ & $\begin{array}{c}\% \text { within } \\
\text { weight }\end{array}$ & $\begin{array}{c}\% \text { within } \\
\text { occlusion }\end{array}$ & $\begin{array}{c}\% \text { within } \\
\text { weight }\end{array}$ & $\begin{array}{c}\% \text { within } \\
\text { occlusion }\end{array}$ \\
\hline Shunt Occlusion & $30.0 \%$ & $54.5 \%$ & $80.0 \%$ & $36.4 \%$ & $6.7 \%$ & $9.1 \%$ \\
\hline$P$ value & \multicolumn{7}{|c|}{$0.006 *$} & \\
\hline
\end{tabular}

*: statistically significant difference

B) Intra-operative details Eighty-five percent of shunts in our study have been performed through a median sternotomy incision while $15 \%$ were performed via a thoracotomy incision either right or left. This is similar to the study of McKenzie et al in which $65 \%$ of patients were operated upon via sternotomy approach ${ }^{(17)}$. Whereas the majority of shunts in Shauq et al's study were done via thoracotomy route $(53.3 \%)^{(15)}$. In Odim et al's series half of patients were done via sternotomy approach and half of them via thoracotomy approach $^{(22)}$. We needed cardiopulmonary bypass in $27.5 \%$ of patients; due to desaturation and hemodynamic instability during pulmonary artery clamping. Just $6 \%$ of patients in Dirks et al's study needed $\mathrm{CPB}^{(3)}$. In $35 \%$ of patients in our series we used a $4 \mathrm{~mm}$ Goretix shunt. In $32.5 \%$ of patients a $3.5 \mathrm{~mm}$ shunt was used and in $22.5 \%$ a $3 \mathrm{~mm}$ shunt was used. The least frequent shunt size used in our study is the $5 \mathrm{~mm}$ graft. This can be explained by the observation that most of our patients are infants and the 4-mm graft is the most suitable for most of them according to their weight. This agrees with the results of González de Dios et $\mathrm{al}^{(12)}$ who used a $4 \mathrm{~mm}$ shunt in the 
majority of their patients (77\%). However Tsai et al used a $5 \mathrm{~mm}$ Goretix shunt in $51.2 \%$ of their patients and only $20.9 \%$ of shunts were performed using a $4 \mathrm{~mm}$ shunt ${ }^{(23)}$. This difference is due to that over $60 \%$ of their patients were older than one year of age. Concerning the site of the shunt $77.5 \%$ of our patients have been offered a right- sided MBTS as reported in most of the literature. For example McKenzie et al performed a right sided shunt in $90 \%$ of their patients ${ }^{(17)}$ and $95 \%$ of patients according to Gladmann et al received a right- sided shunt ${ }^{(5)}$. However Maghur et al performed $89 \%$ of their shunt procedures on the left side ${ }^{(16)}$. Ligation of the ductus arteriosus is not a standard technique in our study. We have ligated the PDA in $52.5 \%$ of patients. This depends on the anatomy of the pulmonary artery branches and whether there is origin stenosis affecting the branch pulmonary artery which receives the ductus. This is similar to the findings of Zahorec et al in which PDA was closed in $50 \%$ of patients ${ }^{(7)}$. All our patients were heparinized before arterial clamping and just $10 \%$ have received intraoperative protamine to reverse the effect of systemic heparinisation.

Table 8: Relationship between shunt occlusion and graft size

\begin{tabular}{|c|c|c|c|c|}
\hline & & & $\begin{array}{c}\text { shunt } \\
\text { occlusion }\end{array}$ & $\begin{array}{c}\mathrm{P} \\
\text { value }\end{array}$ \\
\hline \multirow{4}{*}{$\begin{array}{l}\frac{N}{N} \\
\frac{+}{N} \\
\frac{\pi}{v}\end{array}$} & $3 \mathrm{~mm}$ & $\begin{array}{l}\mathrm{N} \\
\% \text { within graft size } \\
\% \text { within Shunt- occlusion }\end{array}$ & $\begin{array}{c}6 \\
66.7 \% \\
54.5 \%\end{array}$ & \multirow{4}{*}{$0.022 *$} \\
\hline & $3.5 \mathrm{~mm}$ & $\begin{array}{l}\mathrm{N} \\
\% \text { within graft size } \\
\% \text { within Shunt- occlusion }\end{array}$ & $\begin{array}{c}2 \\
15.4 \% \\
18.2 \% \\
\end{array}$ & \\
\hline & $4 \mathrm{~mm}$ & $\begin{array}{l}\mathrm{N} \\
\% \text { within graft size } \\
\% \text { within Shunt- occlusion }\end{array}$ & $\begin{array}{c}3 \\
21.4 \% \\
27.3 \% \\
\end{array}$ & \\
\hline & $5 \mathrm{~mm}$ & $\begin{array}{l}\mathrm{N} \\
\% \text { within graft size } \\
\% \text { within Shunt- occlusion }\end{array}$ & $\begin{array}{l}0 \\
0 \\
0\end{array}$ & \\
\hline
\end{tabular}

C) Post-Operative Conditions and Incidence of Different Complications

Oxygen saturation post-operatively has risen to a mean of $77.3 \pm 12.41 \%$ and ranged from 40 to $90 \%$. Al Jubair et al demonstrated a mean post-operative oxygen saturation of $83 \pm 17.9 \%{ }^{(13)}$. The mean duration of mechanical ventilation is $3.88 \pm 2.89$ days. The mean duration of ICU stay is $6.35 \pm 4.86$ days while the mean duration of hospital stay is $7.8 \pm 5.919$ days. Longer stay in the ICU and the hospital is associ- ated with more morbidities related to the surgical intervention. In Sivakumar et al's series the mean duration of mechanical ventilation was $2 \pm 2.83$ days the mean duration of ICU stay was $4.79 \pm 2.66$ days and the mean duration of hospital stay was $11.7 \pm 6.4$ days $^{(10)}$. Post-operative phentolamine has been used in just $22.5 \%$ of our patients due to its lack in the local market. The incidence of mortality in our study is $50 \% .25 \%$ of deaths occurred in the first post-operative day and 50\% of mortality 
cases were recorded in the first three days post-operatively. The main causes for death in the early post-operative period are shunt occlusion (55\%) and shunt overflow causing heart failure (30\%) and these complications usually manifest themselves early in the post-operative course; explaining why most of mortality cases in our series occurred in the first few days after the surgical intervention. Reviewing the literature our recorded incidence of mortality is relatively high. Dirks et al reported a $9 \%$ mortality rate(3). The discharge mortality in Petrucci et al's study was $7.2 \%$ with $33 \%$ of deaths occurring within the first post-operative 24 hours $^{(4)}$. Gedicke et al reported a very low incidence of mortality in their series; $3.9 \%(14)$ while it was $11 \%$ in Swain et al's study ${ }^{(21)}$. An outstanding mortality record of $4 \%$ was reported in Myers et al's series despite studying only those under $3 \mathrm{~kg}^{(18)}$. The incidence of acute shunt occlusion in our study is $\mathbf{2 7 . 5 \%}$. This is relatively high compared to other studies. For example the incidence of acute shunt thrombosis in Bove et al's study ${ }^{(24)}$ was $5 \%$ and it was $3 \%$ in Maghur et al's study ${ }^{(16)}$. Of special importance these $3 \%$ did not receive postoperative heparin in contrary to our study in which both intra-operative and postoperative heparin is standard for all patients. Dirks et al reported an incidence for acute shunt blockage of $9 \%$; none of them associated with mortality ${ }^{(3)}$ whereas
$21.4 \%$ of shunt occlusion cases in Guzzetta et al's study (accounting for $6.8 \%$ of the study population) died ${ }^{(6)}$. Another $20 \%$ of our patients have suffered from shunt overflow eventually leading to intractable acute heart failure. This is also high in comparison to Bove et al's study. They reported a $7.5 \%$ incidence of shunt overshunting ${ }^{(24)}$. One of the most serious postoperative complications noticed in a significant proportion of our patients is wound infection. It complicated $30 \%$ of our patients and several infection control strategies have been implicated both intra- and post-operatively. For example, the antibiotic regimens both first and second lines have been continuously reviewed considering the periodic culture and sensitivity results from the wounds and ICU. There is a $10 \%$ incidence of sepsis in our patients and $15 \%$ suffered from ventilator-associated pneumonia (VAP). Concerning extubation failure it complicated $40 \%$ of our patients. This is relatively high in comparison to Gupta et al's study which reported an incidence of $27 \%$ for extubation failure ${ }^{(25)}$. Only $15 \%$ of our patients necessitated reopening in the early postoperative period; of whom $66.6 \%$ were reopened due to shunt occlusion and $33.3 \%$ for wound debridement. Shunt reintervention was reported in $17 \%$ of patients in Myerset al's study ${ }^{(18)}$ while it was reported to be $9.3 \%$ by Alkhulaifi et al ${ }^{(11)}$.

Table 9: Relationship between shunt overflow and MAPCAs

\begin{tabular}{|l|c|c|c|c|}
\hline & \multicolumn{4}{|c|}{ MAPCAs } \\
\hline & Without MAPCAs (n=5) & With MAPCAs (n=3) \\
\hline & $\begin{array}{c}\text { \% within } \\
\text { MAPCAs }\end{array}$ & $\begin{array}{c}\text { \% within } \\
\text { overflow }\end{array}$ & $\begin{array}{c}\text { \% within } \\
\text { MAPCAs }\end{array}$ & $\begin{array}{c}\% \text { within } \\
\text { overflow }\end{array}$ \\
\hline Shunt Overflow & $13.9 \%$ & $62.5 \%$ & $75.0 \%$ & $37.5 \%$ \\
\hline P value & \multicolumn{4}{|c|}{$0.004 *$} \\
*: statistically significant difference
\end{tabular}

D) Risk Factors for Mortaltiy

In our series $55 \%$ of mortality cases were related to shunt occlusion while $30 \%$ died due to shunt overflow and just 10\% died because of sepsis. This contrasts with Dirks et al's work which proved that none 
of shunt occlusion cases have died(3). Also Gedicke et al have reported that none of mortality cases were associated with shunt blockage ${ }^{(14)}$. Sivakumar et al documented that $50 \%$ of mortality cases were associated with shunt failure while the other $50 \%$ were due to sepsis(10). Within the mortality cases in our study $55 \%$ are infants below one year of age and $40 \%$ are neonates while just $5 \%$ are children. However, the highest mortality rate is observed in the neonatal age group (61.5\%). This observation is not statistically significant. This discrepancy may be explained by the fact that most of our patients are infants, so they contribute largely even to the mortality cases. This agrees with most of the literature. For example Maghur et al had the same observation of increased mortality in neonates ${ }^{(16)}$. Also Al Jubair et al reported $6.4 \%$ mortality incidence in those younger than one week old 3.7\% in those between one week and one year old and $0.5 \%$ in those over one year old(13). Both genders contribute equally to the mortality cases however $58.8 \%$ of females died while the mortality incidence in males is $43.5 \%$. This relationship is not statistically significant. As far as weight of our patients is concerned in the analysis of mortality there is a statistically significant relationship between them. Weight less than $3 \mathrm{~kg}$ carries a especially high risk for mortality; as $80 \%$ of patients in this category died in our study. However, $60 \%$ of deaths were observed in those between 3 and 4 $\mathrm{kg}$ and patients less than $3 \mathrm{~kg}$ only contribute to $20 \%$ of deaths. Again, this is because most of our patients are between 3 and $4 \mathrm{~kg}$. This agrees with the results of $\mathrm{Al}$ Jubair et al(13) Petrucci et al ${ }^{(4)}$ and González de Dios et al ${ }^{(12)}$. Alkhulaifi $A$ et al found that weight less than $2 \mathrm{~kg}$ is a risk factor for mortality in their study ${ }^{(11)}$. In our study mortality was found to be especially high in cases of single ventricle physiology (55.5\%) while $38.4 \%$ of patients with biven- tricular pathologies were reported to die. All cases of CAVCSD PA and TA TGA died and $50 \%$ of patients with PA / VSD died while mortality in patients with PA / IVS is $66.7 \%$. This is not statistically significant. Bove et al ${ }^{24)}$ reported the following mortality incidences: $14 \%$ in PA/ VSD $18 \%$ in PA/ IVS $13 \%$ in single ventricle physiology and no mortality was reported in patients with TOF TGA or Ebstein anomaly. In McKenzie et al's study mortality was $15 \%$ in single ventricle physiology and $3 \%$ in patients with biventricular hearts ${ }^{(17)}$. Ebstein anomaly was a risk factor for mortality in their study and these observations were statistically significant. PA/IVS and single ventricle physiology were statistically significant risk factors for mortality in Petrucci et al's series (4). Diagnosis other than TOF was a risk factor for mortality in Maghur et al's study ${ }^{(16)}$. A statistically significant risk factor for mortality in our study is urgency and the need for preoperative prostaglandin E2 infusion. 90\% of urgent cases and those in need for prostaglandin E2 infusion died while 63.3\% of elective cases survived. All patients who necessitated pre-operative mechanical ventilation have died however this is statistically insignificant. This agrees with the results of Maghur at al ${ }^{(16)}$ Petrucci et al $^{(4)}$ and Alkulaifi et al ${ }^{(11)}$. There was a statistically nonsignificant relationship between the surgical approach and the mortality in our study. About $53 \%$ of the patients in median sternotomy group died while $33.3 \%$ of patients in both right and left thoracotomy groups died. Alkhulaifi et al also found no statistically significant relationship between the surgical approach and mortality ${ }^{(11)}$. However McKenzie et al found a statistically significant association between mortality and surgical approach; sternotomy was a risk factor for mortality in their study ${ }^{(17)}$. Similarly Odim et al reported a $11.5 \%$ mortality incidence in the sternotomy group and only a 5.8\% mortali- 
ty incidence in the thoracotomy group and this was a statistically significant relationship ${ }^{(22)}$. Concerning Cardiopulmonary Bypass, it is a well-established risk factor for mortality in our study; $90.9 \%$ of patients in whom CPB was used died while $34.5 \%$ of patients not necessitating CPB died. This is consistent with the results of McKenzie et al who established a statistically significant relationship between CPB and mortality ${ }^{(17)}$. As far as the target pulmonary artery branch size is considered there is no statistically significant relationship with the mortality despite about $60 \%$ of those with pulmonary artery branch less than $4 \mathrm{~mm}$ died and only $39 \%$ of those with pulmonary artery branch more than $4 \mathrm{~mm}$ died. This does not agree with the results of Al Jubair et al who observed decreased mortality with PA branch diameter less than $4 \mathrm{~mm}$. However this was statistically non-significant ${ }^{(13)}$. Mortality in our study was observed to decrease with increasing shunt size and this is a statistically significant relationship. $89 \%$ of patients with shunt $3 \mathrm{~mm}$ died while no deaths were recorded in patients with shunt $5 \mathrm{~mm}$. Perhaps this is because patients necessitating a shunt $3 \mathrm{~mm}$ almost always have other significant risk factors for mortality. However Myers et al found no statistically significant relationship between shunt size and mortality ${ }^{(18)}$. In patients with surgically ligated PDA intraoperatively mortality incidence was $38 \%$ while it was $59 \%$ in patients whose PDA was not ligated. This relationship is not statistically significant. However González de Dios et al found that PDA closure was a risk factor for early mortality in their study ${ }^{(12)}$. In our study patients with wound infection had lower incidence of mortality (25\%) while $60 \%$ of patients without wound infection died. This relationship is statistically significant. Concerning sepsis complicating a proportion of our patients due to wound infection and VAP it is a non-significant risk factor for mortality; $75 \%$ of patients with sepsis died while $47 \%$ of patients without sepsis died. Sivakumar et al reported a $5 \%$ mortality incidence in their study contributed to sepsis(10).

\section{E) Risk Factors for Shunt Occlusion}

Eleven of our patients were complicated by acute shunt occlusion. 6 of them (54.5\%) are neonates in whom the incidence of shunt occlusion is $46 \%$. The incidence of acute shunt occlusion in infants is $16 \%$. However, this observation is not statistically significant. Tsai at al showed a statistically significant relationship between age and shunt patency(23). Weight of our patients was a significant risk factor for acute shunt blockage; $80 \%$ of those less than $3 \mathrm{~kg}$ suffered from shunt occlusion. The incidence was $30 \%$ in those between 3 and $4 \mathrm{~kg}$ and $6.7 \%$ in those more than $4 \mathrm{~kg}$. Al Jubair et al noticed that early shunt failure increased significantly in patients less than $3 \mathrm{~kg}^{(13)}$. This agrees with the results of Gedicke et al ${ }^{(14)}$. Concerning the surgical approach there was no statistically significant relationship between it and acute shunt failure in our study. Odim et al found that the incidence of acute shunt occlusion was significantly higher in thoracotomy group (19.2\%) compared to sternotomy group $(7.7 \%)^{(22)}$. There was a statistically significant relationship between the graft size and acute shunt occlusion in our study; $66.7 \%$ of patients with a 3-mm shunt suffered from acute blockage while no occlusion was reported with $5 \mathrm{~mm}$ shunts. Small shunt size was a significant risk factor for shunt reinterventions in the studies of $\mathrm{O}^{\prime}$ Connor et $\mathrm{al}^{(8)}$ and Myers et al ${ }^{(18)}$. Tsai et al reported that graft size was a risk factor for shunt occlusion ${ }^{(23)}$. $36.4 \%$ of patients with target pulmonary artery branch less than $4 \mathrm{~mm}$ suffered from acute shunt occlusion while $16.7 \%$ of those with pulmonary artery branch less than $4 \mathrm{~mm}$ were complicated 
by occlusion but this is statistically nonsignificant. Guzzetta et al found that PA size was a significant risk factor for shunt occlusion $^{(6)}$ whereas Al Jubair et al found no statistical significance as regards PA diameter and acute shunt failure ${ }^{(13)}$.

\section{Conclusion}

The study concludes that the main risk factors for mortality that proved statistical significance were weight as mortality rates decreased with increasing weight urgency pre-operative prostene infusion cardiopulmonary bypass graft size as mortality decreased with increasing graft size and wound infection. Age echo diagnosis pre-operative mechanical ventilation surgical approach size of branch pulmonary arteries PDA ligation and MAPCAs did not have a statistically significant impact on mortality. Regarding shunt occlusion weight shunt size and intra-operative administration of protamine were statistically significant risk factors. Whereas preoperative diagnosis of MAPCAs was the only risk factor for shunt overflow. Indeed, shunt overflow and ventilatorassociated pneumonia were risk factors for extubation failure.

\section{References}

1. Chikwe J et al. Oxford Specialist Handbook of Cardiothoracic Surgery. 2ndedition.Oxford University Press 2013.

2. Demiricin $M$, Doğan $R$, Ozkan $M$, Ozsoy F, Kuzgun E, Güvener $M$. Perigraft seroma complicating the modified Blalock-Taussig shunts: two consecutive instances with review of literature. Turk J Pediatr 2004; 46 (3):275-8.

3. Dirks V, Prêtre R, Knirsch W, et al. Modified Blalock Taussig shunt: a notso-simple palliative procedure. Eur $\mathrm{J}$ Cardiothorac Surg. 2013;44(6):1096102.
4. Pettrucei $O, O^{\prime} B r i e n ~ S M$, Jacobs $M L$, Jacobs JP, Manning PB, Eghtesady P. Risk factors for mortality and morbidity after the neonatal Blalock Taussig shunt procedure. Ann Thorac Surg. $2011 ; 92(2): 642-51$

5. Gladman G, McCrindle BW, Williams WG, Freedom RM, Benson LN. The modified Blalock Taussig shunt: Clinical impact and morbidity in Fallot's tetralogy in the current era. J ThoracCardiovasc Surg. 1997 ;114(1):25-30

6. Guzzetta NA, Foster GS, Mruthinti N, Kilgore PD, Miller BE, Kanter KR. InHospital shunt occlusion in infants undergoing a modified Blalock Taussig shunt. Ann Thorac Surg. 2013;96 (1):176-82.

7. Zahorec M, Hrubsova Z, Skrak P, Poruban $R$, Nosal $M$, Kovacikova L. A comparison of Blalock-Taussig shunts with and without closure of the ductus arteriosus in neonates with pulmonary atresia. Ann Thorac Surg. $2011 ; 92(2): 653-8$.

8. O'Connor MJ, Ravishankar C, Ballweg JA. et al. Early systemic-to-pulmonary artery shunt intervention in neonates with congenital heart disease. J Thorac Cardiovasc Surg. $2011 ; 142(1)$ :10612.

9. Ahmad U, Fatimi S, Naqvi I. et al. Modified Blalock-Taussig Shunt: Immediate and Short-Term Follow-Up Results in Neonates. Heart Lung Circ. 2008; 17(1):54-8.

10. Sivakumar K, Shivaprakasha K, Rao SG, Kumar RK. Operative outcome and intermediate term follow-up of neonatal Blalock- Taussig shunts. Indian Heart J. 2001;53(1):66-70.

11. Alkhulaifi AM, Lacour-Gayet F, Serraf A, Belli E, Planché C. Systemic pulmonary shunts in neonates: early clinical outcome and choice of surgical approach. Ann Thorac Surg. 2000; 69(5):1499-504.

12. González de Dios J, Blanco Bravo D, Burgueros Valero M. et al. Perioperative management of systemic pulmonary shunts in the neonatal period. An Esp Pediatr. 1993 ;39(2):139-48. 
13. Al Jubair KA, Al Fagih MR, Al Jarallah AS. et al. Results of 546 BlalockTaussig shunts performed in 478 patients. Cardiol Young. 1998;8(4):48690.

14. Gedicke M, Morgan G, Parry A, Martin R, Tulloh R. Risk Factors for Acute Shunt Blockage in Children after Modified Blalock Taussig Shunt operations. Heart Vessels. 2010;25 (5):405-9.

15. Shauq A, Agarwal V,_Karunaratne A, et al. Surgical approaches to the blalock shunt: does the approach matter? Heart Lung Circ. 2010 ;19(8):460-4.

16. Maghur HA, Ben-Musa AA, Salim ME, Abuzakhar SS. The modified BlalockTaussig shunt: a 6-year experience from a developing country. Pediatr Cardiol. 2002; 23 (1):49-52.

17. McKenzie ED, Khan MS, Samayoa AX. et al. The Blalock-Taussig shunt revisited: a contemporary experience. J Am Coll Surg. 2013; 216 (4):699-704

18. Myers JW, Ghanayem NS, Cao Y. et al. Outcomes of systemic to pulmonary artery shunts in patients weighing less than $3 \mathrm{~kg}$ : analysis of shunt type size and surgical approach. J Thorac Cardiovasc Surg. 2014;147(2):672-7.

19. Williams JA, Bansal AK, Kim BJ. et al. Two thousand Blalock-Taussig shunts: a six-decade experience. Ann Thorac Surg. 2007;84(6):2070-5.
20. Fermanis GG, Ekangaki AK, Salmon AP. et al. Twelve-year experience with the modified Blalock-Taussig shunt in neonates. Eur J Cardiothorac Surg. 1992; 6(11):586-9.

21. Swain SK, Dharmapuram AK, Reddy $P$ Ramdoss N, Raghavan SS, Kona SM. Neonatal Blalock-Taussig shunt: technical aspects and postoperative management. Asian CardiovascThorac Ann. 2008; 16(1):7-10.

22. Odim J, Portzky M, Zurakowski D. et al. Sternotomy Approach for the Modified Blalock-Taussig Shunt. American Heart Association 1995; 92:256-61.

23. Tsai KT, Chang CH, Lin PJ. Modified Blalock Taussig shunt: Statistical analysis of potential factors influencing shunt outcome. J Cardiovasc Surg (Torino). 1996 ;37 (2):149-52.

24. Bove T, Vandekerckhove K, Panzer J, De Groote K, De Wolf D, François K. Disease- specific outcome analysis of palliation with the modified BlalockTaussig shunt. World J PediatrCongenit Heart Surg. $2015 ; 6(1): 67-74$.

25. Gupta P, McDonald R, Goyal S. et al. Extubation failure in infants with shunt-dependent pulmonary blood flow and univentricular physiology. Cardiol Young. 2014 ;24(1):64-72. 